\title{
Process Performance Management - Identifying Stereotype Problem Situations as a Basis for Effective and Efficient Design Research
}

\author{
Anne Cleven, Felix Wortmann, and Robert Winter \\ Institute of Information Management, University of St. Gallen \\ Mueller-Friedberg-Strasse 8, 9000 St. Gallen, Switzerland \\ \{anne.cleven, felix.wortmann, robert.winter\} @unisg.ch
}

\begin{abstract}
Just recently many organisations get involved with process performance management (PPM). It appears, however, that PPM initiatives confront organisations with multi-faceted and complex challenges that call for a detailed problem analysis before any solution is developed. In this paper we introduce two patterns for identifying stereotype problem situations in design research (DR) and apply one to the field of PPM. The application gives detailed insights into typical PPM problem situations and illustrates the usefulness of our approach.
\end{abstract}

Keywords: Design Research, Design Science, Process Performance Management, Problem Definition.

\section{Introduction}

In today's hypercompetitive and globalized world measuring and in particular managing organisational performance is obligatory [8]. Hence, a myriad of frameworks has been developed during the last few decades each focussing on a somewhat different set of performance-related aspects [20]. Only few of these frameworks, however, put an emphasis on processes as the primary performance management object [20]. Likewise have performance issues been widely neglected in available business process management (BPM) approaches and systems so far. BPM systems are in fact "still very much workflow management systems (WfMS) and have not yet matured in the support of the BPM diagnosis" [32]. Although some software suites provide features like business activity monitoring (BAM) or audit trails the generation of meaningful reports or the prediction of process trends are still only rarely feasible [32]. Elbashir et al. [18] thus propose that effectively managing performance on a process level requires bringing together BPM on the one hand and business intelligence (BI) capabilities and techniques on the other. As the case may be, it is undisputed that a prerequisite for the development of a suitable PPM solution is a detailed analysis of the respective problem situation. Within the information systems (IS) research community the DR approach has been recognised as a valuable approach for rigorously developing useful problem solutions. With respect to how problem situations should be identified, however, there still is a lack of guidance as will be shown below. 
The aim of this paper thus is twofold: Firstly, we seek to suggest two different approaches that offer advice on how to identify stereotype problem situations in DR in general. Secondly, applying one of the proposed approaches we strive for understanding the nature of stereotype PPM problem situations in particular. We address these objectives by first providing a conceptual background including a brief overview over the current DR literature and the concepts of BPM, BI and PPM (section 2). Subsequently, we propose two approaches for identifying stereotype problem situations and apply the first approach in the field of PPM (section 3). The concluding section 4 summarizes and discusses our approach and gives an outlook on future work.

\section{Background}

\subsection{Design Research}

The DR paradigm has been discussed thoroughly in recent years and is just now gaining ground as a valued contributor to both "building knowledge and improving practice" $[39$, p. 8$]$ in the IS discipline. As opposed to natural and social research DR does not crave ultimate truths, grand theories or general laws, but seeks to identify and understand problematic real-world situations and transform these into more desired states by creating solutions that hurdle the respective dilemma $[38,52]^{1}$. A number of authors have proposed reference processes sketching the activities that are essential for DR [25, $26,38,39,44,50]$. Juxtaposing these approaches it becomes evident that the following six activities are commonly perceived as constituent for the DR process: (I) 'identify problem/need', (II) 'define objectives/requirements', (III) 'develop solution', (IV) 'evaluate', (V) 'reflect and theorize', and (VI) 'communicate/publish findings'. Owing to the fact that the DR process may either generate new research interests or uncover that the developed solution turns out unsatisfactory (or both) it is often described as cyclic or iterative $[25,26,44]$. With respect to DR output forms - commonly referred to as artefact types - March and Smith were the first to conceive a systemization. In their well-known 1995 paper they proposed the following four artefact types: constructs, models, methods, and instantiations [38]. Among others Walls et al. [60, 61], Venable [59] and Gregor [22] argue that theories, too, can and should be regarded as an essential fifth artefact type. Since DR represents a subfield of the IS discipline which aims at purposefully designing artefacts that address human and organisational problems [1], purely organisational as opposed to solely information technology (IT)-related artefacts may as well be seen as appropriate outcomes of DR [63].

As mentioned above DR artefacts are developed with the overall objective of transforming unsatisfactory real-world situations into more desired ones. The appropriateness or usefulness of a planned solution for a certain problem is thereby greatly contingent upon the unique factors that characterise the problem situation. Some researchers like Fiedler [19] in his work on the so-called 'Contingency Model' or Mitroff in his work on wicked problems [41] have emphasized the importance of thoroughly

${ }^{1}$ While DR as one part of IS design science research is aimed at creating solutions to specific classes of problems and thus involves the actual 'building', design science (DS) reflects on the artefact development process and - as such - involves research into the 'building' $[49,63]$. 
analyzing and defining investigated problems in order to reveal their distinct characteristics. Up to now, however, extant DR literature has not incorporated these insights. Quite the contrary, while the analysis and specification of the problem situation within a DR project is of utmost importance for the success of the whole project it has so far not received much academic attention (as opposed to e.g. evaluation, which has been considered in great detail, cf. [3, 9, 47, 48]).

March and Smith, two of the very early authors of DR in IS, do not address the necessity of analyzing the problem situation at all [38]. Hevner et al. in their much-cited MISQ paper admittedly realize the importance of examining the 'environment', stating that "business needs are assessed and evaluated within the context of organisational strategies, structure, culture, and existing business processes" [26, p. 79]. Nonetheless, they do not provide any normative or prescriptive guidelines on how to actually assess the business needs in their specific context. Peffers et al. emphasize the importance of the "knowledge of the state of the problem" [44, p. 55] for effectively providing a solution. Further advice, however, only gets as specific as the recommendation that "it may be useful to atomize the problem conceptually so that the solution can capture its complexity." [44, p. 52]

\subsection{Business Process Management}

Although adjusting a business's activities along its value chain - as opposed to its functions or departments - had already been suggested by Nordsieck as early as in 1934 [43] the actual change from a vertical, functional to a horizontal, process oriented organisational structure only proceeded in the late 1980s. Especially Porter [45], Hammer and Champy [24], and Davenport [13] have contributed to the paradigm shift and promote a holistic and customer-focused process-orientation [15]. Nowadays, BPM is a well-established concept and a number of authors have developed a great variety of different approaches.

Across these approaches BPM is commonly understood as a set of methods, techniques, and tools to continuously (re-) design, enact, analyze, control and improve the an organisation's fundamental operational activities [34, 58, 64]. While putting different emphases in their works the majority of researchers agree in that BPM consists of four main processes that are affiliated with and build on each other, namely: (I) 'process definition, design and modelling', (II) 'process implementation and enactment', (III) 'process monitoring and controlling', and (IV) 'process optimisation and refinement'. Kueng and Krahn survey that in quite a number of today's organisations performance measurement and assessment on a process level is realized only in a mediocre way [33].

\subsection{Business Intelligence}

One of the very first persons to use the term 'business intelligence' (BI) was Hans Peter Luhn in his 1958 article "A Business Intelligence System" [36]. While in this early stage the perception of BI had a slightly different tinge and was mainly restricted to systemand technology-related issues, later definitions reflect the business-proximity and the methodological character of the concept. Today, BI (often likewise called business analytics) may be defined as "concepts and methods to improve business decision 
making by using fact-based support systems" [46, par. IV.2] and constitutes a crucial component within a company's management reporting infrastructure. BI systems provide decision makers with timely, relevant, and easy to use information and can be defined as "specialized tools for data analysis, query, and reporting, (such as OLAP and dashboards)" [18, p. 138]. They are complemented by special IT infrastructure such as data warehouses, data marts, and "Extract, Transform and Load" tools which are required for their deployment and effective use [18].

BI serves a multitude of different purposes. Such being the case, Sircar calls it the "latest battlefield" [53, p. 293] for organisations striving for either survival or - even more ambitious - for a competitive advantage in nowadays global and fiercely rival business environment. The concept holds a bundle of analytical capabilities that allows organisations to effectively use their data and keep track of how exactly their business performs. These capabilities reach from retrospective, descriptive analyses, answering questions like 'What happened?' and 'Where exactly was the problem?' to futureoriented, predictive analyses, answering questions like 'What happens if these trends continue?' and 'What will happen next?' [14]. Descriptive or core analytics thus facilitate quick reactions or corrections, whereas predictive analytics allow for the anticipation of future values like, for example, customer needs. Current research issues in the field of BI are said to cover the quantification, measurement and evaluation of BI systems benefits and improved tactics for efficiently managing the BI processes within organisations $[27,35]$.

\subsection{Process Performance Management}

Organisational performance has an imperative influence on both the actions of companies and their competitiveness. Thus, the development of means for accurately measuring this performance has highly occupied researchers and practitioners in recent years $[31,37,42]$. The following list represents a digest of dimensions that are included in existing performance measurement frameworks: cost, quality, productivity, flexibility, efficiency, growth, processes, customer satisfaction, delivery, and environment $[8,20]$. As of lately, a shift is perceptible that is taking the focus from the pure measurement of performance to a broader view of an actual management of performance $[2,20]$. Performance Management can then be defined as "the use of performance measurement information to effect positive change in organisational culture, systems and processes" [20, p. 674].

Performance measurement and management systems address a variety of different aspects of performance, like in production planning [30] or cost accounting [17]. Only few, however, enable an organisation to effectively manage its performance on the level of business processes. Elbashir et al. state that the use of BI systems is obligatory for a company seeking to enhance its business process performance via measures like cost reduction and productivity improvement [18]. Some currently available WfMS provide rudimentary process monitoring and control functions but "have not yet matured in the support of the BPM diagnosis." [32, p. 748]. Ko et al. further point out that some software suites include BAM dashboards and facilitate the creation of useful audit trails but the generation of "meaningful reports displaying process trends still requires external specialized reporting tools" [32, p. 749]. 


\section{Identifying Fundamental PPM Problem Situations}

\subsection{Two Approaches for the Identification of Problem Situations}

As has been pointed out in section 2.1 extant DR literature has only on the surface touched the question of how to exactly analyse the problem situation under consideration and how to identify and specify its unique characteristics. However, like with any other research endeavour specifying the exact problem situation is inevitably necessary in order to prevent both wasted time and money [11]. In this section we set out to propose two related approaches for the task of rigorously analysing a DR problem. The approaches may be interpreted as patterns as they are known and frequently used in the field of object-oriented programming [21]. A pattern describes a pair of a regularly recurring problem and a respective general solution. The general solution serves as a template that can be reused for fastening the problem solving process for a certain problem-class. The subsequently proposed patterns provide two general variants for systematically examining the specific characteristics of DR problems.

A major subfield of the IS discipline deals with software design and software engineering [4]. It is this subfield that we consulted when developing our approaches. A software development project always starts off with a detailed analysis of the exact functional and non-functional conditions and needs the planned software or system has to meet - the requirements engineering (RE) [5]. In their seminal 1998 book Sommerville and Kotonya, two authors who can be called pre-eminent in the field of RE, identified four essential activities for the RE process, namely: (I) 'requirements elicitation', (II) 'requirements analysis and negotiation', (III) 'requirements documentation', and (IV) 'requirements validation' [54]. The two herein proposed approaches relate to the first two activities of this process. The first approach, named Lean Situation Identification Process is depicted on the left-hand side of Fig. 1, whereas the second, named Rich Situation Identification Process is shown on the right-hand side. As there is never a "one-size-fits-all" solution to a problem [6], both approaches aim at identifying a number of different starting positions organisations may commence from. This allows for the development of solutions as close to the actual requirements as possible. Subsequently, the approaches are described in detail.

When starting a DR project the very first step concerns the identification of the problem to be solved. The problem may either be identified deductively by means of a literature analysis or be apprehended directly from real-world incidents [56]. In order to achieve a deeper understanding of the problem situation as relates to its very specific characteristics and to facilitate both a higher relevance and utility of the final solution(s) we propose to conduct an empirical investigation based on a survey. In order to identify fundamental, i.e. stereotype problem situations thus a questionnaire needs to be developed based on knowledge to be acquired in the area under investigation (cf. Fig. 1, phase (1) in both processes). Thereon, the questionnaire must be distributed to a population big and representative enough to warrant a reliable impression of the different situation stereotypes (cf. Fig. 1 phase (2) in both processes). While the two patterns proposed herein work alike during the phase of requirements elicitation, they differ with regard to the phase of requirements analysis and negotiation. 


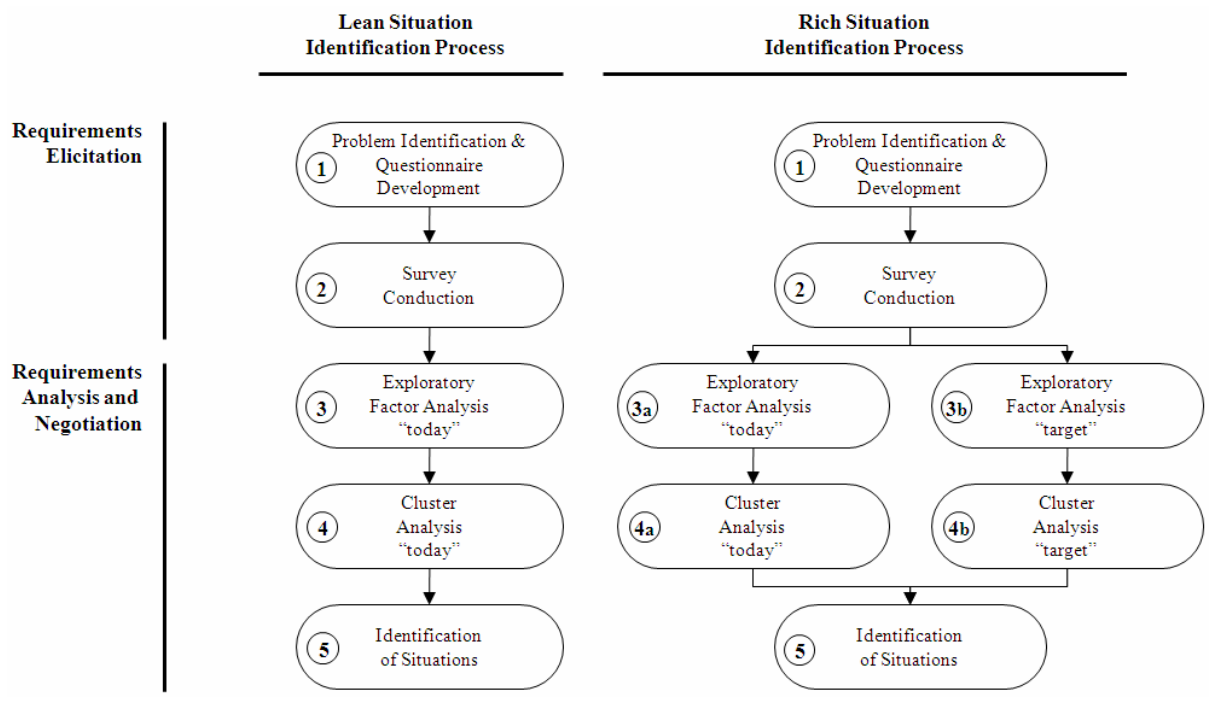

Fig. 1. DR Problem Situation Identification Patterns

The Lean Situation Identification Process is applied if the respondents selected for the survey are under time pressure and have a limited amount of time, whereas the Rich Situation Identification Process may be employed if the respondents have a considerable amount of time. In the first pattern the survey participants are only asked to answer the questionnaire as to how they conceive the current situation within their organisations ("today"). In contrast, the second pattern includes the investigation of the target situation, too. The actual analysis now begins with an exploratory factor analysis (EFA) which serves the purpose of developing a deeper understanding of the characteristics of the current problem situation (cf. Fig. 1 phase 3 in the first approach and phase $3 \mathrm{a}$ in the second) and those of the targeted situation ( $3 \mathrm{~b}$ in the second approach). In general, EFA serves the identification of a number of important and mutually independent factors from a multiplicity of contingent variables [10]. Subsequently, the question of whether there are common situations which feature the same characteristics can be tackled using cluster analysis. A cluster analysis serves the purpose of partitioning a set of observations into subsets that are homogeneous within and heterogeneous amongst each other [23]. Again, the first pattern exclusively addresses the current situation, whereas the second also reveals situations the organisations polled are targeting at. Both approaches conclude with an interpretation of the identified clusters (cf. Fig. 1, phase (5) in both processes).

Either of the two approaches is associated with some specific assumptions as well as advantages and disadvantages. The Lean Situation Identification Process shows the clear advantage of having half as many questionnaire items as the second approach. Consequently, the analyses are only half as elaborate. However, the first approach comes along with the assumption that irrespective of the individual starting situation all companies are striving for one ideal target situation in which each of the identified factors or characteristics describing the starting position will be maximised. The characteristics of the first approach are briefly summarised in the following table. 
Table 1. Characteristics of the Lean Situation Identification Process

\begin{tabular}{l}
\hline Usage Scenarios \\
- Respondents have a limited amount of time for questionnaire completion \\
- Exploratory analysis with a considerable amount of items \\
\hline Advantages \\
\hline - Lightweight questionnaire covering "today" questions only \\
- Lightweight analysis (only one factor and one cluster analysis) \\
- Low number of situations (cluster "today") results in less complex artefact construction \\
and validation process \\
\hline Disadvantages \\
\hline Situations are derived on the assumption that companies strive for a general improve- \\
ment in regards to all factors, i.e. one ideal target situation exists
\end{tabular}

The second approach, too, features some specifics. Also addressing the targeted situation, it produces a much bigger deal of work. In return, it allows for a much more precise analysis of the requirements for each situation by facilitating a detailed migration analysis from initial to target situations. The following table briefly summarises the features of the second approach.

Table 2. Characteristics of the Rich Situation Identification Process

\section{Usage Scenarios}

- Respondents have a considerable amount of time for questionnaire completion

- Confirmatory analysis with a limited amount of items

\begin{tabular}{l}
\hline Aadvantages \\
\hline - Situations precisely depict the requirements \\
\hline Disadvantages \\
- Time consuming questionnaire covering "today" and "target" questions \\
- Complex analysis ( two factor and two cluster analyses) \\
- High number of situations (cluster "today" x cluster "target") results in complex arte- \\
fact construction and validation process
\end{tabular}

Subsequently, we will apply the first pattern - the Lean Problem Situation Identification Process - for the examination of typical problem situations in the field of PPM.

\subsection{Lean PPM Problem Situation Identification}

\subsubsection{Problem Identification and Questionnaire Development}

As has been pointed out in the previous section gaining knowledge through reviewing existing literature in the field under investigation is essential for the development of the questionnaire (cf. section 3.1, [12]). As PPM represents a multidisciplinary field of study that builds on a variety of concepts, methods and techniques from other research areas, the most important ones being BPM, BI and performance management [40] the following sections represent the major building blocks of the questionnaire:

- BPM: BPM is a fundamental pillar for PPM. Thus, the questionnaire contains items addressing the degree to which an organisation is process oriented. Consequently, factors like clear process responsibilities (process officers) [51] and 
well-defined process documentation are covered. Moreover, the degree of consistent and transparent processes across systems and organisation are taken into account [7].

- BI: BI serves as the information backbone of PPM (cf. section 2.4). As welldefined BI responsibilities and processes are a prerequisite for effective and efficient information delivery, the questionnaire comprises both aspects. Furthermore, data integration and data quality are key for holistic and reliable PPM. Therefore, data integration and quality are also covered by the questionnaire.

- PPM: Moreover, the questionnaire contains items addressing what organisations actually measure (i.e., process cycle time, process costs, process quality). Furthermore, the data set covers information on where measures are deployed (i.e., production processes, sales processes). Finally, the questionnaire asks for the process performance management approach of organisations. Specifically, if process performance management is integrated into an overarching management approach (i.e., Balanced Scorecard, Corporate Performance Management) and if the plan-do-check-act cycle is applied for PPM.

\subsubsection{Survey Conduction}

The questionnaire was distributed at a BI and DWH practitioner event held in October 2009. The participants were specialists and executives, working in the field of BI and DWH on both the IT and the business side thus having the required knowledge and information to answer the questions [12]. The questionnaire was designed to assess the current state of PPM in the participating organisations. Respective statements were formulated, and the respondents were requested to indicate current values for the degree of realization of each variable using a five-tiered Likert scale. Before being used, the questionnaire was pretested, both on an individual item level in early phases and as a whole before finally being distributed [12].

A total of 49 questionnaires were returned. If a data set was incomplete, i.e. if one or more than one of the 21 items was missing, the questionnaire was disregarded. On the basis of this criterion, 45 questionnaires were selected for further analysis. Although the data set is rather small, the sample can be considered adequate for the purpose of an EFA [16]. The interviewed organisations are primarily large and medium-sized companies from the German-speaking countries. 60\% have more than 1000 employees and another $22 \%$ have more than 100 employees. The sectors mainly represented were professional services (40\%), banking, finance and insurance (29\%), high tech $(11 \%)$ manufacturing and consumer goods $(7 \%)$, media and telecommunication $(5 \%)$, and others $(8 \%)$.

\subsubsection{Exploratory Factor Analysis}

The EFA was performed on the data set covering 21 items. The measure of sampling adequacy (MSA, "Kaiser-Meyer-Olkin criterion") for the data set is 0.777. MSA represents an indicator for the extent to which the input variables belong together and provides information on whether a factor analysis can reasonably be performed or not. Kaiser and Rice appraise a value of 0.7 or more as "reasonable", i.e. the data set is considered to be appropriate for applying EFA [29, 55]. Five factors that jointly explain about $75.6 \%$ of the total variance were extracted by means of principal component analysis. Both the Kaiser criterion and the scree plot point to this solution. The resulting component matrix was rotated using the Varimax method with Kaiser normalization in order to improve the interpretability of the items' assignment to the factors [28]. The rotated component matrix is depicted in Table 3. 
Table 3. Factor loadings

\begin{tabular}{|c|c|c|c|c|c|}
\hline Item description & F1 & $\mathrm{F} 2$ & F3 & F4 & F5 \\
\hline \multicolumn{6}{|l|}{$\begin{array}{l}\text { Factor (1) Broad, PDCA-based use of PPM measures } \\
\text { Eigenvalue }=9.510 ; \text { Variance explained }=45.287 \%\end{array}$} \\
\hline Adherence to schedules is measured for processes. & .834 & .304 & .059 & .165 & .102 \\
\hline Capacity utilization is measured for processes. & .787 & .345 & .332 & .202 & .083 \\
\hline Quality is measured for processes. & .758 & .209 & .228 & .202 & .190 \\
\hline Process resource utilisation is measured. & .735 & .395 & .069 & .060 & .059 \\
\hline Process costs are measured. & .728 & .362 & .305 & .067 & -.030 \\
\hline Process cycle times are measured. & .723 & .221 & .324 & .331 & .190 \\
\hline The plan-do-check-act (PDCA) cycle is applied for PPM. & .543 & .168 & .214 & .415 & .308 \\
\hline \multicolumn{6}{|l|}{$\begin{array}{l}\text { Factor (2) BPM maturity } \\
\text { Eigenvalue }=2.530 ; \text { Variance explained }=12.049 \%\end{array}$} \\
\hline $\begin{array}{l}\text { Process flows are consistent and transparent beyond func- } \\
\text { tional borders (organisational unit, division and depart- } \\
\text { ment). }\end{array}$ & .239 & .796 & .284 & .045 & .063 \\
\hline Processes have defined process officers. & .203 & .765 & .057 & .105 & .044 \\
\hline Processes are consistently documented and/or modelled. & .321 & .758 & -.062 & .180 & .216 \\
\hline $\begin{array}{l}\text { Process flows are consistent and transparent beyond sys- } \\
\text { tem borders. }\end{array}$ & .404 & .718 & .358 & -.047 & .167 \\
\hline Process orientation is a central paradigm. & .289 & .660 & -.110 & .220 & .046 \\
\hline \multicolumn{6}{|l|}{$\begin{array}{l}\text { Factor (3) PPM process diffusion } \\
\text { Eigenvalue = 1.527; Variance explained }=7.269 \%\end{array}$} \\
\hline PPM also covers non-financial measures. & .034 & -.047 & .843 & .280 & -.121 \\
\hline PPM is deployed for purchasing processes. & .282 & .156 & .797 & .158 & .003 \\
\hline PPM is deployed for production processes. & .260 & -.064 & .714 & .272 & .249 \\
\hline PPM is deployed for sales processes. & .268 & .394 & .702 & .008 & .137 \\
\hline \multicolumn{6}{|l|}{$\begin{array}{l}\text { Factor (4) BI-enabled, integrated PPM } \\
\text { Eigenvalue }=1.209 ; \text { Variance explained }=5.759 \%\end{array}$} \\
\hline $\begin{array}{l}\text { Defined BI governance responsibilities and processes are } \\
\text { in place. }\end{array}$ & .033 & .270 & .134 & .775 & .094 \\
\hline $\begin{array}{l}\text { PPM is part of the enterprise-wide Balanced Score Card } \\
\text { (BSC). }\end{array}$ & .392 & -.031 & .387 & .750 & -.020 \\
\hline $\begin{array}{l}\text { PPM is part of the Corporate Performance Management } \\
\text { (CPM). }\end{array}$ & .297 & .153 & .469 & .613 & .102 \\
\hline \multicolumn{6}{|l|}{$\begin{array}{l}\text { Factor (5) High quality information base } \\
\text { Eigenvalue }=1.109 ; \text { Variance explained }=5.283 \%\end{array}$} \\
\hline $\begin{array}{l}\text { A central integrated data base is in place (e.g., an Enter- } \\
\text { prise Data Warehouse). }\end{array}$ & .009 & .125 & .018 & .107 & .907 \\
\hline Data quality is consistently high. & .279 & .128 & .075 & .023 & .814 \\
\hline
\end{tabular}

The five factors constitute themselves as follows:

- There are seven items loading on the first factor, in the following referred to as Broad, PDCA-based use of PPM measures. All of the items are metric-related and address two questions: a) what is measured in the context of PPM (which key performance indicators (KPIs) are used), and b) how is the measurement accomplished. Process KPIs explicitly addressed by this factor are adherence to schedule, capacity utilization, process quality, process resource utilization, 
process costs and process cycle times. The plan-do-check-act (PDCA) cycle is applied for KPI management.

- All five BPM-related items were found to have significant impact on the second factor, accounting for the degree of BPM maturity. Organisations having a high BPM maturity, advocate process orientation as a central paradigm, foster process documentation/modelling and clear process responsibilities thereby assuring consistent process flows across organisations and systems.

- Another four items load high on the third factor, representing PPM process diffusion. This factor expresses the degree of KPI usage in core business processes (covering procurement, production and sales activities). Furthermore, this factor strengthens the importance of non-financial measures.

- Three variables were found to have significant impact on the fourth factor, subsequently referred to as BI-enabled, integrated PPM. Organisations showing a high performance regarding this factor rely on well-defined, well-coordinated processes and management approaches in performance management as well as in BI. In these companies PPM is part of an integrated and comprehensive management approach i.e. BSC or CPM. To enable concepts like BSC or CPM defined BI governance responsibilities and processes are in place.

- Finally, there are two variables loading on the fifth factor, in the following referred to as High quality information base. According to our analysis, companies having a high quality information base build upon a central integrated data store (e.g., an Enterprise Data Warehouse) thereby assuring consistently high data quality across the organisation.

\subsubsection{Cluster Analysis}

In order to identify organisations with similar problem situations, cluster analysis is used. The cluster analysis is based on factor scores being calculated using the regression method [57]. The Ward fusion algorithm and the squared Euclidean distance are applied for clustering, as this combination finds very good partitions resulting in an appropriate number of clusters and similar number of observations in each cluster [23, 62]. On the basis of the dendrogram, i.e. the graphical representation of the fusion process and the cluster sizes the final number of clusters was defined [23]. Table 4 contains the arithmetic means of the factor scores for each of the four clusters.

Table 4. Arithmetic means of factors per cluster

\begin{tabular}{lcccccc}
\hline Cluster & $\mathrm{n}$ & $\mathrm{F} 1$ & $\mathrm{~F} 2$ & $\mathrm{~F} 3$ & $\mathrm{~F} 4$ & $\mathrm{~F} 5$ \\
\hline Cluster 1 & 11 & -0.264 & -0.214 & 0.206 & -0.559 & -1.159 \\
\hline Cluster 2 & 16 & -0.234 & 0.301 & -0.069 & -0.605 & 0.702 \\
\hline Cluster 3 & 11 & 0.743 & -0.626 & -0.599 & 0.580 & 0.056 \\
\hline Cluster 4 & 7 & -0.220 & 0.632 & 0.775 & 1.351 & 0.127 \\
\hline
\end{tabular}

\subsubsection{Identification of Situations}

For an easier interpretation and better comparison the cluster means in Fig. 2 are standardized: It depicts how many standard deviations a cluster value (cluster means from Table ) is above or below the overall factor mean (across all cluster values). 


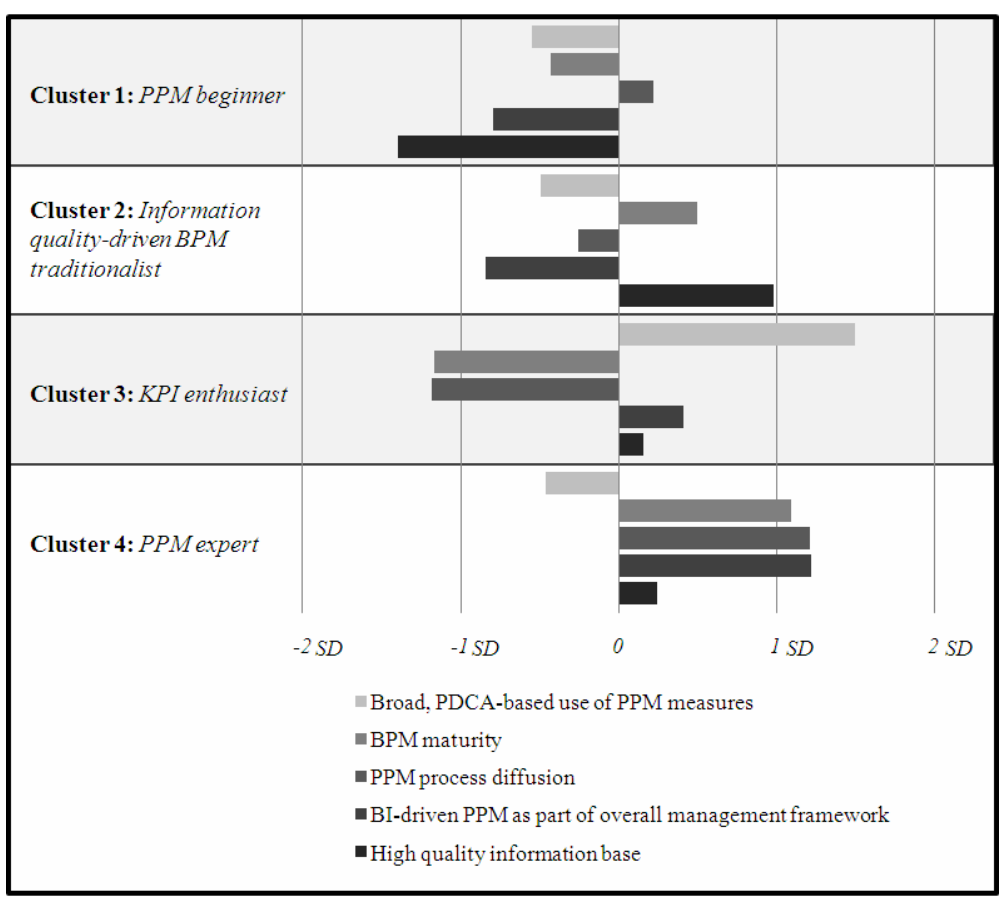

Fig. 2. Standardized arithmetic means of factors per cluster

The four clusters can be interpreted as follows:

- Cluster 1 - PPM beginner: The first cluster is characterized by poor performance regarding four of the five factors. Only PPM process diffusion, i.e. the degree of KPI usage in core business processes is at an above average level. The organisations of this cluster show a significant lack of performance in regards to a high quality information base. Neither from a BI perspective nor from a BPM perspective are fundamental concepts in place that could be leveraged as a basis for PPM.

- Cluster 2 - Information quality-driven BPM traditionalist: The second cluster shows positive performance with respect to BPM and information quality. BPM as well as information quality form a solid basis for PPM. Nevertheless, all three PPM related factors show low performance. Companies of this cluster specifically lack well-defined, well-coordinated processes and management approaches in performance management as well as in BI.

- Cluster 3 - KPI enthusiasts: The third cluster is characterized through high BI and low BPM performance. The extend to which KPIs are employed, appears very ambiguous: On the one hand the number of different measures in place is very high. On the other only a very small number of business processes are being measured.

- Cluster 4 - PPM expert: Companies of the fourth cluster show a high performance across four of the five factors. The only low performing factor is factor one: In contrast to the KPI enthusiasts, PPM experts apply PPM to a significant number of their business processes building upon a consistent set of limited metrics. 
The above described clusters represent typical problem situations, or 'points of departure' organisations may commence from when getting involved with PPM. These stereotype situations may now serve as a basis for defining the objectives of any type of artefact required to support the respective PPM initiative.

\section{Conclusion and Future Research}

The aim of this paper was twofold: For one thing, we sought to suggest two patterns offering advice on how to identify stereotype problem situations in DR in general. For another thing, by applying the first of the proposed patterns we aimed at understanding the nature of stereotype PPM problem situations in particular. With the former we hope to contribute to the extant DR literature by providing a rigorous and yet easy-touse way for systematically analysing the specific characteristics of a problem under investigation. Applying the approach in the context of PPM a) in fact revealed four distinct problem situations that mark the 'point of departure' for possible PPM projects and $b$ ) showed that the approach provides valuable assistance for analysing a DR problem. We do, however, not want to restrain that there is need for further research: In their current version the patterns are not yet deeply elaborated and approved, and surely need further evaluation and refinement. Moreover, the patterns assist a design researcher in gaining a first good understanding of a problem situation. Most certainly, however, additional deeper analyses will be required for the actual building of artefacts. Not least, the applicability of the second pattern has to be assessed and both patterns should be used in further contexts to carve out potential deficiencies.

\section{References}

1. Alter, S.: Work Systems and IT Artifacts - Does the Definition Matter? Commun. Assoc. Inf. Syst. 17(14), 2-41 (2006)

2. Amaratunga, D., Baldry, D.: Moving from Performance Measurement to Performance Management. Facil. 20(5/6), 217-223 (2002)

3. Baskerville, R., Pries-Heje, J., Venable, J.: Soft Design Science Research: Extending the Boundaries of Evaluation in Design Science Research. In: 2nd International Conference on Design Science Research in Information Systems and Technology, Pasadena, CA (2007)

4. Benbasat, I., Zmud, R.W.: The Identity Crisis within the IS Discipline: Defining and Communicationg the Discipline's Core Properties. Manag. Inf. Syst. Quart. 27(2), 183-194 (2003)

5. Berenbach, B., Paulish, D., Kazmeier, J., Rudorfer, A.: Software \& Systems Requirements Engineering: In Practice. McGraw-Hill, New York (2009)

6. Bucher, T., Klesse, M., Kurpjuweit, S., Winter, R.: Situational Method Engineering - On the Differentiation of "Context" and "Project Type". In: IFIP WG8.1 Working Conference on Situational Method Engineering - Fundamentals and Experiences, pp. 33-48. Springer, Geneva (2007)

7. Bucher, T., Winter, R.: Taxonomy of Business Process Management Approaches: An Empirical Foundation for the Engineering of Situational Methods to Support BPM. In: vom Brocke, J., Rosemann, M. (eds.) Handbook on Business Process Management. Springer, Heidelberg (2010) (to be published) 
8. Carton, R.B., Hofer, C.W.: Measuring Organizational Performance. Metrics for Entrepreneurship ans Strategic Management Research. Edward Elgar Publishing Limited, Cheltenham (2006)

9. Cleven, A., Gubler, P., Hüner, K.: Design Alternatives for the Evaluation of Design Science Research Artifacts. In: 4th International Conference on Design Science Research in Information Systems and Technology, Philadelphia, PA (2009)

10. Conway, J.M., Huffcutt, A.I.: A Review and Evaluation of Exploratory Factor Analysis Practices in Organizational Research. Organ. Res. Meth. 6(2), 147-168 (2003)

11. Creswell, J.W.: Research Design. Qualitative, Quantitative, and Mixed Methods Approaches. Sage Publications, Inc., Thousand Oaks (2003)

12. Czaja, R., Blair, J.: Designing Surveys - A Guide to Decisions and Procedures. Pine Forge Press, Thousand Oaks (1996)

13. Davenport, T.H.: Process Innovation. Reengineering Work through Information Technology. Information Technology. Harvard Business Press, Boston (1993)

14. Davenport, T.H., Harris, J.G.: Competing on Analytics. Harvard Business School Publishing Corporation, Boston (2007)

15. de Toro, I., McCabe, T.: How to Stay Flexible and Elude Fads. Qual. Prog. 30(3), 55-60 (1997)

16. de Winter, J.C.F., Dodou, D., Wieringa, P.A.: Exploratory Factor Analysis With Small Sample Sizes. Multivar. Behav. Res. 44, 147-181 (2009)

17. Durden, C.H., Hassel, L.G.: Cost accounting and performance measurement in a just-intime production environment. Asia Pac. J. Manag. 16(1), 111-115 (1999)

18. Elbashir, M.Z., Collier, P.A., Davern, M.J.: Measuring the Effects of Business Intelligence Systems: The Relationship between Business Process and Organizational Performance. Int. J. Account. Inf. Syst. 9, 135-153 (2008)

19. Fiedler, F.E.: A Contingency Model of Leadership Effectiveness. Adv. Exp. Soc. Psychol. 1, 149-190 (1964)

20. Folan, P., Browne, J.: A review of performance measurement: Towards performance management. Comput. Ind. 56, 663-680 (2005)

21. Gamma, E., Helm, R., Johnson, R., Vlissides, J.: Design Patterns: Elements of Reusable Object-Oriented Software. Addison-Wesley Professional, Reading (1994)

22. Gregor, S.: Design Theory in Information Systems. Australasian J. Inf. Syst. 10, 14-22 (2002)

23. Hair, J.F.J., Black, W.C., Babin, B.J., Anderson, R.E., Tatham, R.L.: Multivariate Data Analysis. Pearson Prentice Hall, Upper Saddle River (2006)

24. Hammer, M., Champy, J.: Reengineering the Corporation - A Manifesto for Business Revolution. HarperCollins Publishers, New York (1993)

25. Hevner, A.R.: A Three Cycle View of Design Science Research. Scand. J. Inf. Syst. 19(2), 87-92 (2007)

26. Hevner, A.R., March, S.T., Park, J., Ram, S.: Design Science in Information Systems Research. Manag. Inf. Syst. Quart. 28(1), 75-105 (2004)

27. Jourdan, Z., Rainer, K., Marshall, T.E.: Business Intelligence: An Analysis of the Literature. Inf. Syst. Manag. 25, 121-131 (2008)

28. Kaiser, H.F.: The Varimax Criterion for Analytic Rotation in Factor Analysis. Psychometrika 23(3), 187-200 (1958)

29. Kaiser, H.F., Rice, J.: Little Jiffy, Mark IV. Educ. Psychol. Meas. 34(1), 111-117 (1974)

30. Karacapilidis, N.I., Pappis, C.P.: Production planning and control in textile industry: A case study. Comput. Ind. 30(2), 127-144 (1996) 
31. Keegan, D., Eiler, R., Jones, C.: Are your performance measures obsolete? Manag. Account. 70(12), 45-50 (1989)

32. Ko, R.K.L., Lee, S.S.G., Lee, E.W.: Business process management (BPM) standards: a survey. Bus. Process Manag. J. 5, 744-791 (2009)

33. Kueng, P., Krahn, A.: Building a Process Performance Measurement System - Some Early Experiences, in: Journal of Scientific and Industrial Research. Journal of Scientific and Industrial Research 58(3/4), 149-159 (1999)

34. Lee, R.G., Dale, B.G.: Business Process Management: A Review and Evaluation. Bus. Process Manag. J. 4(3), 214-225 (1998)

35. Lönnqvist, A., Pirttimäki, V.: The Measurement of Business Intelligence. Inf. Syst. Manag, 32-40 (Winter 2006)

36. Luhn, H.P.: A Business Intelligence System. IBM J. Res. Dev. 2(4), 314-319 (1958)

37. Lynch, R., Cross, K.: Measure Up - The Essential Guide to Measuring Business Performance. Mandarin, London (1991)

38. March, S.T., Smith, G.F.: Design and natural science research on information technology. Decis. Support Syst. 15(4), 251-266 (1995)

39. Marshall, P., McKay, J.: A Review of Design Science in Information Systems. In: 16th Australasian Conference on Information Systems, Sydney, Australia, pp. 1-11 (2005)

40. Melchert, F., Winter, R., Klesse, M.: Aligning Process Automation and Business Intelligence to Support Corporate Performance Management. In: Tenth Americas Conference on Information Systems (AMCIS 2004), New York, NY, USA, pp. $4053-4063$ (2004)

41. Mitroff, I.I.: William James and a Theory of Thinking. J. Inf. Technol. Theory Appl. 6(2), 83-89 (2004)

42. Neely, A., Adams, C., Kennerley, M.: The Performance Prism: The Scorecard for Measuring and Managing Business Success. Prentice Hall, London (2002)

43. Nordsieck, F.: Grundlagen der Organisationslehre. Poeschel, Stuttgart (1934)

44. Peffers, K., Tuunanen, T., Rothenberger, M.A., Chatterjee, S.: A Design Science Research Methodology for Information Systems Research. J. Manag. Inf. Syst. 24(3), 45-77 (2007)

45. Porter, M.E.: Competitive Strategy: Techniques for Analyzing Industries and Competitors. Free Press, New York (1980)

46. Power, D.J.: A Brief History of Decision Support Systems, http://dssresources.com/history/dsshistory.html

47. Pries-Heje, J., Baskerville, R., Venable, J.: Strategies for Design Science Research Evaluation. In: 16th European Conference on Information Systems, Galway, Ireland, pp. 255-266 (2008)

48. Pries-Heje, J., Venable, J., Baskerville, R.: A Risk Management Framework for Design Science Research. In: 31st Information Systems Research Seminar in Scandinavia, Åre, Sweden, pp. 1-18 (2008)

49. Purao, S., Baldwin, C., Hevner, A., Storey, V.C., Pries-Heje, J., Smith, B., Zhu, Y.: The Sciences of Design: Observations on an Emerging Field. Commun. Assoc. Inf. Syst. 23, 523-546 (2008)

50. Rossi, M., Sein, M.: Design Research Workshop: A Proactive Research Approach. Presentation delivered at IRIS 26,

http://tiesrv.hkkk.fi/iris26/presentation/

workshop_designRes.pdf

51. Samson, D., Challis, D.: Patterns of Business Excellence. Meas. Bus. Excell. 6(2), 15-21 (2002)

52. Simon, H.A.: The Sciences of the Artificial. The MIT Press, Cambridge (1969) 
53. Sircar, S.: Business Intelligence in the Business Curriculum. Commun. Assoc. Inf. Syst. 24(17), 289-302 (2009)

54. Sommerville, I., Kotonya, G.: Requirements Engineering. Processes and Techniques. Wiley, New York (1998)

55. Stewart, D.W.: The Application and Misapplication of Factor Analysis in Marketing Research. J. Mark. Res. 18(1), 51-62 (1981)

56. Swamidass, P.M.: Empirical Science: New Frontier in Operations Management Research. Acad. Manag. Rev. 16(4), 793-814 (1991)

57. Thompson, B.: Exploratory and Confirmatory Factor Analysis: Understanding Concepts and Applications. American Psychological Association, Washington (2004)

58. van der Aalst, W.M.P., ter Hofstede, A.H.M., Weske, W.: Business Process Management: A Survey. In: van der Aalst, W.M.P., ter Hofstede, A.H.M., Weske, M. (eds.) BPM 2003. LNCS, vol. 2678, pp. 1611-3349. Springer, Heidelberg (2003)

59. Venable, J.R.: The Role of Theory and Theorising in Design Science Research. In: 1st International Conference on Design Science Research in Information Systems and Technology, Claremont, CA, pp. 1-18 (2006)

60. Walls, J., Widmeyer, G., Sawy, O.E.: Building an Information System Design Theory for Vigilant EIS. Inf. Syst. Res. 3(1), 36-59 (1992)

61. Walls, J.G., Widmeyer, G.R., El Sawy, O.A.: Assessing information system design theory in perspective: how useful was our 1992 initial rendition. J. Inf. Technol. Theory Appl. 6(2), 43-58 (2004)

62. Ward Jr., J.H.: Hierarchical Grouping to Optimize an Objective Function. J. Am. Stat. Assoc. 58(301), 236-244 (1963)

63. Winter, R.: Design science research in Europe. Eur. J. Inf. Syst. 17, 470-475 (2008)

64. Zairi, M.: Business Process Management: A Boundaryless Approach to Modern Competitiveness. Bus. Process Manag. J. (1997) 